\title{
Cellular Uptake Properties of the Complex Derived from Quantum Dots and G8 Molecular Transporter
}

\author{
Jungkyun Im, Kaustabh K. Maiti, Wanil Kim, ${ }^{\dagger}$ Kyong-Tai Kim, ${ }^{\dagger}$ and Sung-Kee Chung* \\ Department of Chemistry, Pohang University of Science and Technology, Pohang 790-784, Korea \\ ${ }^{*}$ E-mail: skchung@postech.ac.kr \\ ${ }^{\dagger}$ Department of Life Science, Pohang University of Science and Technology, Pohang 790-784, Korea \\ Received January 28, 2011, Accepted February 21, 2011
}

\begin{abstract}
The biotin-attached G8 molecular transporter (5) was synthesized and used together with quantum dots in preparing the complexes (QD-MT). The QD-MT complexes were studied in terms of the cellular uptake and the internalization mechanism in live HeLa cells with the aid of various known endocytosis inhibitors. It has been concluded that the QD-MT complex is internalized largely by macropinocytosis. The mouse tissue distribution of the QD-MT complex by i.p. and i.v. routes showed some organ selectivity and a good ability to cross the BBB.
\end{abstract}

Key Words : Quantum dot, Molecular transporter, Internalization, Macropinocytosis, Blood-brain barrier

\section{Introduction}

Quantum dots (QDs) are fluorescent semiconductor nanocrystals. ${ }^{1}$ Compared to conventional fluorescent dyes, QDs exhibit the following characteristics: 1) Broad absorption spectra combined with narrow and symmetric emission peaks, enable multicolor analysis with a single excitation line and without spectral crosstalk between different detection channels. 2) High quantum yield and excellent photostability make QDs especially suitable for ultrasensitive detection of biomolecules, possibly at the single molecule level. 3) QDs can be detected by electron microscopy, providing their ultrastructural localization in a biological environment. ${ }^{2}$ These advantages make QDs superior to the conventionally used fluorophores such as small organic dyes or fluorescent proteins. Thus as a new class of fluorescent probe, QDs appear attractive for molecular, cellular, and in vivo imaging applications such as real-time imaging of cellular signaling pathways. ${ }^{3}$

However, one of the major problems in using QD nanoparticles for in vivo applications is poor cellular uptake characteristics. While some organic dyes are able to permeate cell membranes by passive diffusion, the size and surface properties of QDs hinder the translocation of QDs across the cellular membranes. Entry of QDs into a cell may be achieved by using a variety of approaches, including electroporation, ${ }^{4}$ and microinjection. ${ }^{5}$ Electroporation temporarily generates hydrophilic pores in the plasma membrane by applying an electric field pulse. The pores allow the passive transport of DNA and QDs into the cell. However, the disadvantages are the low cell viability and the need of special equipments. Microinjection enables the delivery of QDs to the cell's interior in a monodisperse form. But it is a labor intensive process, as individual cells are injected at a time. Besides these physical delivery methods, QDs may be made cell membrane permeable and functionalized by conjugation with surface modifying agents such as lipofectamine, ${ }^{6}$ small peptides, proteins, and nucleic acids. ${ }^{7}$ For example, cell-penetrating peptides (CPPs) such as HIV-I TAT peptide and oligoarginine have been used to facilitate the delivery of QDs into cells. ${ }^{8}$ Uptake of QD by a cell can occur in principle by a single or multiple endocytic pathways such as phagocytosis and pinocytosis. Phagocytosis in mammals is typically confined to specialized cells, including macrophages, monocytes, and neutrophils. They can remove large pathogens or large debris such as the fragments of dead cells, arterial deposits of fat, and so on. ${ }^{9}$ Pinocytosis is a kind of fluid-phase uptake and occurs in all cells by four basic mechanisms: macropinocytosis, clathrin-mediated endocytosis, caveolae-mediated endocytosis, and clathrin- and caveolaeindependent endocytosis. ${ }^{10-14}$ However, the detailed mechanisms of these endocytic processes remain poorly understood.

The cell membrane permeability of QDs largely depends on the surface coatings or the conjugated materials. Previously we developed the G8 (eight guanidine residue containing) molecular transporter built on the sorbitol scaffold, which showed excellent cellular uptake, an affinity toward mitochondria, and high efficiency in crossing the bloodbrain barrier (BBB). ${ }^{15}$ This particular G8 molecular transporter has been successfully demonstrated as a viable delivery vector for various clinically used drugs through the covalent conjugation method. ${ }^{16}$ Now we have investigated the cellular uptake characteristics of the complex (QD-MT) derived from the biotin-attached G8 sorbitol-based molecular transporter (5) and two QDs (QD565 and QD655), and the results are described herein.

\section{Experimental}

\section{Synthesis}

General Methods. Column chromatography was perform- 
ed on Merck 60 silica gel [70-230 or 230-400 mesh (flash)]. All NMR spectra were recorded on a Bruker DPX 300 instrument operating at $300 \mathrm{MHz}$ for ${ }^{1} \mathrm{H}, 75 \mathrm{MHz}$ for ${ }^{13} \mathrm{C}$, unless otherwise stated. MALDI-TOF-MS was obtained on a Micromass M@DI at the Biomolecular Diversity Core Facility (POSTECH). Analytical HPLC was performed on Agilent 1100-HPLC Chemstation with an analytical column ZORBAX C8-monomeric (BU-300, $5 \mu \mathrm{m}, 300 \AA$, $4.6 \times 250$ $\mathrm{mm}$ ), and preparative HPLC with a semi-preparative column GRACEVYDAC C18 $(5 \mu \mathrm{m}, 300 \AA, 10 \times 250 \mathrm{~mm})$.

1-O-Trityl-2,3,4,5-tetra- $O$ - $\left(N\right.$ - $\left\{\right.$ bis-[3- $\left(N^{\prime}, N^{\prime \prime}\right.$-bis-Bocguanidino)-propyl]\}-6-aminooctanoyl)-D-sorbitol (1) was prepared according to a literature procedure. ${ }^{15(\mathrm{a})}$

1-O-( $N$-Benzyloxycarbonyl-6-aminohexanoyl)-2,3,4,5tetra- $O$-( $N$ - $\left\{\right.$ bis-[3-( $N^{\prime}, N^{\prime \prime}$-bis-Boc-guanidino)-propyl]\}6-aminooctanoyl)-6-O-trityl-D-sorbitol (2): To a solution of $1(75.70 \mathrm{mg}, 22.36 \mu \mathrm{mol})$ in $\mathrm{CH}_{2} \mathrm{Cl}_{2}(3 \mathrm{~mL})$ at $\mathrm{rt}$, were added Cbz-protected aminohexanoic acid $(20.77 \mathrm{mg}, 78.29$ $\mu \mathrm{mol})$, EDC (10.72 mg, $55.92 \mu \mathrm{mol})$, and DMAP $(1.40 \mathrm{mg}$, $11.18 \mu \mathrm{mol})$. After stirring for $24 \mathrm{hr}$, the solution was concentrated under reduced pressure. The residue was diluted with EtOAc and then washed with aq. $\mathrm{NaHCO}_{3}$ and brine. The organic layer was dried over $\mathrm{Na}_{2} \mathrm{SO}_{4}$, filtered and condensed in vacuo to give the crude product, which was purified by column chromatography on silica gel to give $\mathbf{2}$ (60 mg, $80 \%$ ) as colorless foamy solid. $R_{f}: 0.38\left(\mathrm{CH}_{2} \mathrm{Cl}_{2}\right.$ : $\mathrm{MeOH}=9: 1) ;{ }^{1} \mathrm{H}$ NMR $\left(\mathrm{CDCl}_{3}, \delta\right) 1.25-1.72(\mathrm{~m}, 206 \mathrm{H})$, 2.29-2.51 (m, 34H), 3.41-3.53 (m, 20H, aromatic protons), 4.00-4.40 (m, $4 \mathrm{H}), 5.08$ (s, $\left.2 \mathrm{H}, \mathrm{C}_{2} \mathrm{Ph}\right), 5.20$ (brs, $\left.1 \mathrm{H}\right), 5.48$ (brs, 1H), 7.25-7.39 (m, 20H), 8.48 (brs, 8H), 11.49 (brs, $8 \mathrm{H}) ;{ }^{13} \mathrm{C} \mathrm{NMR}\left(\mathrm{CDCl}_{3}, \delta\right) 25.11,26.42,27.85,28.70,29.69$, $30.05,34.32,39.90,51.89,53.81,66.85,79.49,83.24$, $127.52,127.64,128.21,128.85,129.05,143.74,153.46$, $156.47,163.99,172.29,172.78,173.12$.

1-O-(Aminohexanoyl)-2,3,4,5-tetra- $O$-( $\left(N\right.$-\{bis-[3-( $\left(N^{\prime}, N^{\prime \prime}-\right.$ bis-Boc-guanidino)-propyl]\}-6-aminooctanoyl)-6-O-tritylD-sorbitol (3): A mixture of $2(49.9 \mathrm{mg}, 13.74 \mu \mathrm{mol})$ and $\mathrm{Pd} / \mathrm{C} 10 \%(80 \mathrm{mg})$ in $\mathrm{CH}_{2} \mathrm{Cl}_{2} / \mathrm{MeOH}(1: 9,8 \mathrm{~mL})$ was stirred under $\mathrm{H}_{2}(\mathrm{~g})(50 \mathrm{psi})$ for $12 \mathrm{hr}$. The reaction mixture was filtered through a short pad of celite and washed with $\mathrm{MeOH}$. Evaporation of the filtrate gave the amino compound 3 (47 $\mathrm{mg}, 98 \%)$ as colorless foamy solid. $R_{f}: 0.10\left(\mathrm{CH}_{2} \mathrm{Cl}_{2}\right.$ : $\mathrm{MeOH}=10: 1) ;{ }^{1} \mathrm{H}$ NMR (MeOD, $\left.\delta\right) 1.22-1.58(\mathrm{~m}, 206 \mathrm{H})$, $1.78-2.21(\mathrm{~m}, 18 \mathrm{H}), 2.33-2.39(\mathrm{~m}, 4 \mathrm{H}), 2.88-3.22(\mathrm{~m}, 16 \mathrm{H})$, 3.47 (brs, 16H), 3.57-3.68 (m, 2H), 4.01-4.21 (m, 2H), 4.66$4.70(\mathrm{~m}, 2 \mathrm{H}), 5.22$ (brs, $1 \mathrm{H}), 5.58$ (brs, $1 \mathrm{H}), 7.27-7.39$ (m, $15 \mathrm{H}$, trityl protons).

1-O-( $N$-Biotin-6-aminohexanoyl)-2,3,4,5-tetra- $O$ - $(N$ - $\{$ bis[3-( $N^{\prime}, N^{\prime \prime}$-bis-Boc-guanidino)-propyl]\}-6-aminooctanoyl)6-O-trityl-D-sorbitol (4): To a solution of $3(35 \mathrm{mg}, 10.01$ $\mu \mathrm{mol})$ in DMF $(1.5 \mathrm{~mL})$, were added biotin $(12 \mathrm{mg}, 49.12$ $\mu \mathrm{mol}), \mathrm{EDC}(4.77 \mathrm{mg}, 24.88 \mu \mathrm{mol}), N$-hydroxybenzotriazole $(1.5 \mathrm{mg}, 11.10 \mu \mathrm{mol})$ and DMAP $(1 \mathrm{mg}, 8.19 \mu \mathrm{mol})$ at rt. After stirring for $24 \mathrm{hr}$ at $\mathrm{rt}$, the solution was concentrated several times at $45^{\circ} \mathrm{C}$ under reduced pressure by azeotropic distillation with toluene. The residue was diluted with aq. $\mathrm{LiCl}(5 \%)$ and then extracted with EtOAc three times. The organic layer was washed with aq. $\mathrm{NaHCO}_{3}$, dried over $\mathrm{Na}_{2} \mathrm{SO}_{4}$, filtered and condensed in vacuo to give the crude product, which was purified by column chromatography on silica gel to give $4(26.1 \mathrm{mg}, 70 \%)$ as colorless foamy solid. $R_{f}: 0.45\left(\mathrm{CH}_{2} \mathrm{Cl}_{2}: \mathrm{MeOH}=10: 1\right) ;{ }^{1} \mathrm{H}$ NMR $\left(\mathrm{CDCl}_{3}, \delta\right) 1.25-$ $1.69(\mathrm{~m}, 206 \mathrm{H}), 2.29-2.49(\mathrm{~m}, 34 \mathrm{H}), 3.45-3.48(\mathrm{~m}, 20 \mathrm{H})$, 3.63-3.76 (m, 16H), 4.29 (brs, 1H), 4.48 (brs, 1H), 4.89 (brs, 3H), 5.11 (brs, 2H), 5.32 (brs, 1H), 5.48 (brs, 1H), 7.27-7.39 (m, $15 \mathrm{H}$, trityl protons), 8.51 (brs, $8 \mathrm{H}$ ), 11.48 (brs, $8 \mathrm{H}$ ); ${ }^{13} \mathrm{C}$ $\mathrm{NMR}\left(\mathrm{CDCl}_{3}, \delta\right) 25.12,25.71,26.33,26.75,28.17,28.46$, $28.71,28.96,29.63,30.09,31.83,34.34,36.88,39.54$, $39.88,51.24,55.73,60.46,62.22,64.15,72.69,79.59$, $83.37,126.30,127.57,128.25,129.08,143.68,153.47$, $156.55,162.93,163.96,172.79,172.81,173.21$.

1-O-( $N$-Biotin-6-aminohexanoyl)-2,3,4,5-tetra- $O$-[ $N$ - $\{$ bis(3-guanidinopropyl)\}-6-aminooctanoyl]-D-sorbitol-8HCl (5): Compound 4 (26 mg, $6.96 \mu \mathrm{mol})$ was added to a solution of EtOAc saturated with gaseous $\mathrm{HCl}(3 \mathrm{~mL})$ at $\mathrm{rt}$, and the solution was stirred for 2 days. After evaporation of solvent, the residue was washed several times with diethyl ether. The precipitate was dissolved in deionized water, filtered through a polytetrafluoroethylene (PTFE) syringe filter, and lyophilized to give the crude product, which was purified by preparative RP-HPLC (GRACEVYDAC, C18),

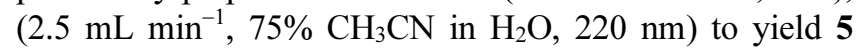
(10.1 mg, 67\%) as white sticky solid. ${ }^{1} \mathrm{H}$ NMR $\left(\mathrm{D}_{2} \mathrm{O}, 500\right.$

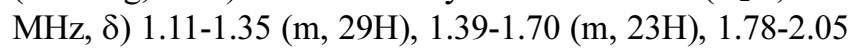
(m, 16H), 2.11-2.48 (m, 11H), 2.65-2.71 (m, 1H), 2.78-2.90 (m, $1 \mathrm{H}), 3.01-3.45(\mathrm{~m}, 40 \mathrm{H}), 3.62-3.88(\mathrm{~m}, 4 \mathrm{H}), 4.15-4.21$ (m, 2H), 4.32 (brs, 1H), 4.55 (brs, 1H), 5.32 (brs, 1H), 5.48 (brs, $1 \mathrm{H}) ;{ }^{13} \mathrm{C}$ NMR $\left(\mathrm{D}_{2} \mathrm{O}, \delta\right) 22.43,22.53,22.70,23.66$, 23.94, 24.94, 25.12, 27.18, 27.26, 27.36, 27.49, 31.61, $33.14,33.31,33.46,35.09,37.50,37.73,49.80,52.52$, $52.71,59.82,61.15,61.65,80.94,121.59,129.79,152.57$, $156.39,162.50,169.29,170.21,174.34,175.08,177.55$, 180.06; MALDI-TOF-MS [M+H] calcd for $\mathrm{C}_{86} \mathrm{H}_{172} \mathrm{~N}_{31} \mathrm{O}_{13} \mathrm{~S}$ $\mathrm{m} / \mathrm{z}$ 1879.3472, found 1879.3036; analytical HPLC (BU300 , at $220 \mathrm{~nm}, 1 \mathrm{~mL} \mathrm{~min}{ }^{-1}, 70 \% \mathrm{CH}_{3} \mathrm{CN}$ in $\mathrm{H}_{2} \mathrm{O}, t_{\mathrm{R}}=2.15$ $\min$ ), purity $99 \%$.

\section{Bioassays}

Materials. Streptavidin conjugated CdSe/ZnS QDs [emission peak at $565 \mathrm{~nm}$ (QD565) or $655 \mathrm{~nm}$ (QD655)] were purchased from Invitrogen Inc. Chloropromazine, sucrose, wortmannin, 5-( $N$-ethyl- $N$-isopropyl)amiloride (EIPA), methyl- $\beta$-cyclodextrin, nystatin, and nocodazole were purchased from Sigma-Aldrich. Hoechst33342, ERtracker green, Mitotracker, Lysotracker, transferrin Texas red conjugate, cholera toxin B Alexa488 conjugate, and dextran Rohdamine B conjugate (MW 10,000) were obtained from Molecular Probes Inc. High glucose Dulbecco's modified Eagle's medium (DMEM), Dulbecco's phosphate buffered saline (PBS, pH 7.4), fetal bovine serum (FBS), and trypsin/EDTA were obtained from Invitrogen. Milli-Q purified water (18.2 $\mathrm{M} \Omega$ ) was used to prepare all aqueous solutions.

Preparation of QD-MT Complex. The QD-MT complex was prepared by incubating the streptavidin conjugated QD (QD-SA, $400 \mathrm{nM}$ ) with biotin-attached molecular trans- 
porter at 1:40 ratio. The mixture was allowed to react for 1 $\mathrm{hr}$ at $\mathrm{rt}$, and then kept at $4{ }^{\circ} \mathrm{C}$ as the stock solution for the QD-MT complex. The excess amount of the molecular transporter is very small, and thus not separated out of the product complex.

Transmission Electron Microscopy (TEM). The samples for electron microscopy were prepared on 300 mesh carboncoated copper grid. A solution of QD565-MT (5 $\mu \mathrm{L}, 30 \mathrm{nM}$ ) was placed on the grid for $5 \mathrm{~min}$, and was gently blotted by Kimwipe. The sample was viewed by TEM (JEM-1011, JEOL, $50 \mathrm{kV}$ ). In order to view streptavidins attached to QDs, an indirect method, i.e. negative staining, was used; $0.5 \%(\mathrm{w} / \mathrm{w})$ of uranyl acetate $(5 \mu \mathrm{L})$ was dropped to the prepared specimen, and after $5 \mathrm{~min}$ it was dried with Kimwipe.

Cell Culture. HeLa cells were cultured at $37{ }^{\circ} \mathrm{C}$ in a humidified 5\% $\mathrm{CO}_{2}$ containing air environment in DMEM and $10 \%(\mathrm{v} / \mathrm{v})$ FBS with antibiotics. The subculture was conducted every 2-3 days using the cells grown to subconfluence.

Cellular Uptake and Localization Experiments. HeLa cells $\left(1 \times 10^{4}\right.$ cells per well $)$ were plated into an 8 -well chambered cover glass (Nalgene Nunc International) and cultured for $48 \mathrm{hr}$. After removing the medium, HeLa cells were washed with PBS (X1). The working concentration of the QD-MT was typically $10 \mathrm{nM}$, and the total volume of the incubation solution in each well was $300 \mu \mathrm{L}$. For the time-course investigation, live HeLa cells were incubated with QD655-MT for 1, 2, 4, and $24 \mathrm{hr}$. QD655 alone was also incubated for $24 \mathrm{hr}$ as a control.

Various kinds of subcellular markers were incubated with the cells in the presence of QD-MT. They include Hoechst33342 (10 $\mu \mathrm{M}, 1 \mathrm{hr}$, a nucleus marker), ERtracker green $(1 \mu \mathrm{M}, 30 \mathrm{~min}$, an endoplasmic reticulum marker), Mitotracker (100 nM, $30 \mathrm{~min}$, a mitochondria marker), and Lysotracker (200 nM, $30 \mathrm{~min}$, a lysosome marker). After incubation, HeLa cells were washed gently with PBS three times and were immersed in cold PBS for imaging with a confocal microscope.

In order to disrupt microtubules, the cells were preincubated with $15 \mu \mathrm{M}$ nocodazole for $30 \mathrm{~min}$ at $37^{\circ} \mathrm{C}$. The drug treated HeLa cells were incubated with QD655-MT for $24 \mathrm{hr}$ and then coincubated with FITC-MT $(10 \mu \mathrm{M})$ for 15 min before confocal microscope imaging.

Each experiment was performed at least twice.

Confocal Laser Scanning Microscopy (CLSM). After incubation, the cell medium was removed from each well. HeLa cells were washed three times with cold PBS, replaced with cold PBS, and then imaged directly on the chambered cover glass. CLSM was performed by using an Olympus Fluoview FV1000 equipped with an N.A. 1.30, 40X, planApo, oil immersion lens. Fluorescence of each fluorophore was analyzed and collected using the following excitation and emission bands: Hoechst33342, $405 \mathrm{~nm}$ (ex), 425-475 $\mathrm{nm}$ (em); FITC and cholera toxin B-Alexa488, $488 \mathrm{~nm}$ (ex), 500-530 nm (em); ERtracker green, $488 \mathrm{~nm}$ (ex), 500-550 nm (ex); QD565, 488 nm (ex), 530-590 nm (em); QD655,
$543 \mathrm{~nm}$ (ex), 630-700 nm (em); transferrin-Texas red, 543 nm (ex), 590-650 nm (em); Mitotracker, Lysotracker, and dextran-Rhodamine B, $543 \mathrm{~nm}$ (ex), 600-700 nm (em). When QT-MT was coincubated with another fluorophore, in order to prevent the crosstalk between different colors of fluorophores, the excitation and the collection of emission were performed sequentially from the individual fluorophores. Merged images and intensity profiles were obtained by the Olympus Fluoview Viewer.

Endocytosis Inhibition Studies. The drugs described below are maintained in the cell medium during incubation with QD-MT or fluorophore-labeled compounds. The cell density was $1 \times 10^{4}$ cells per well and incubation solution was typically $300 \mu \mathrm{L}$ in the 8 -well chambered coverglass. The concentration and incubation time of QD-MT was typically $10 \mathrm{nM}$ and $4 \mathrm{hr}$.

(1) Low Temperature Incubation at $4{ }^{\circ} \mathrm{C}$ : HeLa cells in media were preincubated at $4{ }^{\circ} \mathrm{C}$ for $30 \mathrm{~min}$. Then, cellular incubations with QD655-MT and FITC-MT $(10 \mu \mathrm{M}, 30$ $\mathrm{min}$ ) were carried out at $4{ }^{\circ} \mathrm{C}$. The cells were washed with PBS at $4{ }^{\circ} \mathrm{C}$ prior to fluorescence analysis.

(2) ATP Depletion Experiment: HeLa cells were preincubated in PBS supplemented with $10 \mathrm{mM} \mathrm{NaN}_{3}$ and 50 $\mathrm{mM}$ 2-deoxy-D-glucose for $30 \mathrm{~min}$ at $37{ }^{\circ} \mathrm{C}$, followed by incubation in a solution of QD655-MT and FITC-MT (10 $\mu \mathrm{M}, 30 \mathrm{~min})$.

(3) Clathrin-mediated Endocytosis Inhibition: HeLa cells were preincubated with $30 \mu \mathrm{M}$ chloropromazine in DMEM for $30 \mathrm{~min}$ at $37{ }^{\circ} \mathrm{C}$, followed by incubation with QD655-MT or transferrin Texas red conjugate $\left(25 \mu \mathrm{g} \mathrm{mL}^{-1}\right.$, $1 \mathrm{hr})$.

(4) Hypertonic Incubation: HeLa cells were preincubated at $37{ }^{\circ} \mathrm{C}$ for $30 \mathrm{~min}$ in DMEM supplemented with $0.45 \mathrm{M}$ sucrose. Then, cellular incubations with QD655-MT and Transferrin Texas red conjugate were carried out as described above.

(5) Caveolae-mediated Endocytosis Inhibition: HeLa cells were preincubated with $10 \mathrm{mM}$ methyl- $\beta$-cyclodextrin or $10 \mu \mathrm{g} \mathrm{mL} \mathrm{m}^{-1}$ nystatin in DMEM for $30 \mathrm{~min}$ at $37{ }^{\circ} \mathrm{C}$, followed by incubation with QD655-MT or cholera toxin B Alexa488 conjugate $\left(15 \mu \mathrm{g} \mathrm{mL}{ }^{-1}, 1 \mathrm{hr}\right)$.

(6) Macropinocytosis Inhibition: HeLa cells were preincubated with either $100 \mathrm{nM}$ wortmannin or $100 \mu \mathrm{M}$ EIPA in DMEM for $30 \mathrm{~min}$ at $37{ }^{\circ} \mathrm{C}$. Incubation was followed with QD655-MT or dextran Rhodamine B conjugate $\left(1 \mathrm{mg} \mathrm{mL}{ }^{-1}\right.$, $1 \mathrm{hr})$.

Mouse Tissue Biodistribution Study. All mouse experiments were performed in the POSTECH animal facility in compliance with the relevant laws and institutional guidelines.

For intraperitoneal (i.p.) administration, a solution of QD655-MT $(0.2 \mathrm{nmol})$ in PBS ( $\mathrm{pH} 7.4,500 \mu \mathrm{L})$ was prepared and injected into an eight-week-old mouse (C57BL/6, $22 \mathrm{~g})$. After $24 \mathrm{hr}$, the treated mouse was perfused with

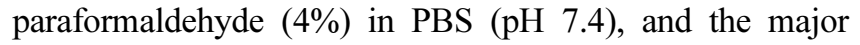
organs (brain, heart, lung, kidney, spleen, and liver) were incubated overnight in a solution of sucrose $(0.5 \mathrm{M})$ in PBS. 
Placed in cryoprotectant, they were cut into $15 \mu \mathrm{m}$ sections with a cryostat and transferred to coated glass slides. After drying, each section was washed with PBS, treated with Triton X-100 (0.3\%) for $15 \mathrm{~min}$ at $\mathrm{rt}$, and then analyzed with an Axioplan2 fluorescence imaging microscope. As a control, triple distilled water $(500 \mu \mathrm{L})$ was also injected into the mouse and treated in the same process. Red fluorescence from QD655-MT in each tissue was compared with the autofluorescence background from the control.

For intravenous (i.v.) injection via tail vein, an elevenweek-old mouse (C57BL/6, $34 \mathrm{~g}$ ) was briefly anesthetized by diethyl ether, and was held in a restraining device. A solution of QD655-MT (0.2 nmol) in PBS (pH 7.4, $500 \mu \mathrm{L})$ was prepared and slowly injected into the tail vein $(5 \mathrm{~cm}$ from distal end) using a plastic $0.5 \mathrm{~mL}$ syringe. Afterwards, some PBS (ca. $30 \mu \mathrm{L})$ was post-injected to flush the tail vein. After $24 \mathrm{hr}$, the administered mouse was perfused with paraformaldehyde (4\%) in PBS ( $\mathrm{pH} 7.4)$, and the rest protocol for specimen preparation and fluorescence imaging was same as described above.

\section{Results and Discussion}

Synthesis of Biotin-attached Sorbitol G8 Molecular Transporter. The $\mathrm{N}$-Cbz-protected aminohexanoic acid was coupled to compound $\mathbf{1}$ under the EDC coupling conditions. The $\mathrm{N}$-Cbz protecting group in $\mathbf{2}$ was removed by hydrogenolysis over $\mathrm{Pd} / \mathrm{C}$ to give 3 in $98 \%$ yield. The resulting amino group was coupled with biotin with EDC, DMAP and HOBT in DMF to furnish 4 . Compound 4 was converted to compound 5 by treatment with ethyl acetate saturated with $\mathrm{HCl}$ gas to remove all the $N$-Boc and trityl protecting groups. The target compound $\mathbf{5}$ was purified by preparative RP-HPLC on a C18 column, and thoroughly characterized by NMR, HPLC, and Maldi-TOF mass spectral analyses (Scheme 1).

Preparation of the Quantum Dot-molecular Transporter Complex (QD-MT) and its Size Determination. The QDMTs were prepared by incubating QD-streptavidin conjugates (QD-SA) with 5 at the molar ratio of 1 to 40 . Since each QD contains 5-10 streptavidins on its surface, and each streptavidin has 4 binding sites available for biotin, about 40 molecules of 5 would be needed to fully occupy all the binding sites of a single QD-SA. The QD-MTs were also prepared by mixing QD-SA and the molecular transporter at lower ratio (1:20). However, this version showed little difference from the higher ratio version except the slightly weaker fluorescence in the cells. Thus, the mixing ratio was kept at 1:40.

The QD565-MT complexes were observed by TEM (JEM-1011, JEOL, $50 \mathrm{kV}$ ). The dark granules indicate the core nanocrystal, and they were well dispersed in PBS without forming larger clusters (Fig. 1(a)). The core size was estimated to be $5 \mathrm{~nm}$. Negative staining of the sample by $0.5 \%$ uranyl acetate did not stain the inside part of streptavidins, thus revealing the periphery of streptavidins (Fig. 1(b)). The dark granules are surrounded by a white disk
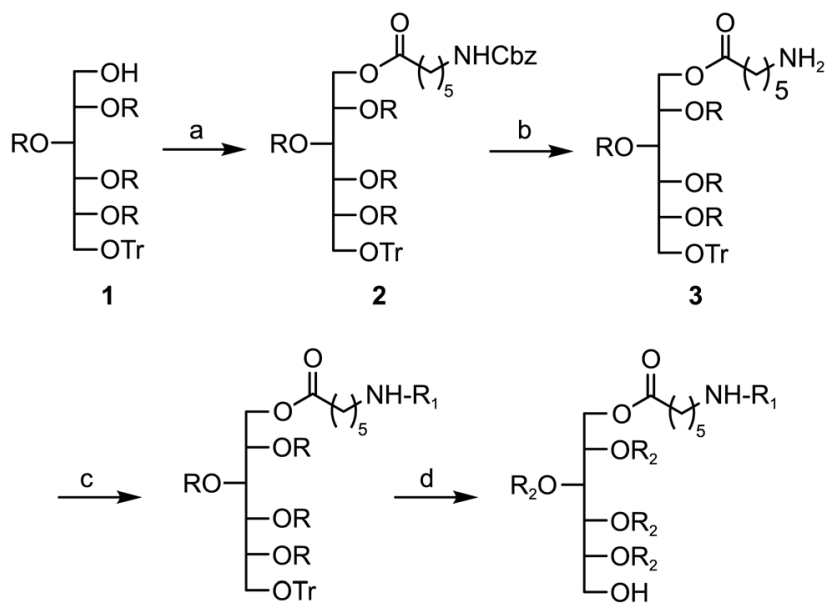

4

5

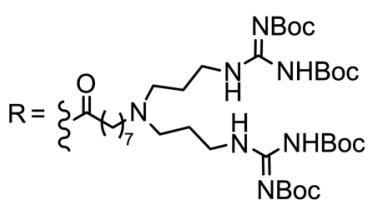<smiles>[R]=[SH]S(=O)CCCC[C@H]1SC[C@H]2NC(=O)N[C@H]21</smiles><smiles>[R]SS(=O)C(C)C(=O)N(CCCNC(N)=NCCl)CCCNC(N)=NCCl</smiles>

Scheme 1. (a) HOOC- $\left(\mathrm{CH}_{2}\right)_{5}-\mathrm{NHCbz}$ EDC, DMAP, $\mathrm{CH}_{2} \mathrm{Cl}_{2}, 24$ hr, $80 \%$; (b) $\mathrm{H}_{2}$ (g) (50 psi), $\mathrm{Pd} / \mathrm{C}, \mathrm{MeOH}-\mathrm{CH}_{2} \mathrm{Cl}_{2}(9: 1), 12 \mathrm{hr}$, 98\%; (c) biotin, EDC, DMAP, HOBT, DMF, rt, 36 hr, 70\%; (d) $\mathrm{HCl}(\mathrm{g})$ in EtOAc, rt, 2 days, $67 \%$.

which is unstained streptavidins. By using this technique, both the QD and the streptavidins could be distinguished, and the size of a single QD565-MT was estimated to be in the range of 18-20 nm (Fig. 1(c)). The QD655-MT complex displayed similar patterns on the TEM analyses.

Cellular Uptake and Intracellular Localization of QDMT. Internalization of QD655-MT in live HeLa cells was observed by confocal laser scanning microcopy (Olympus Fluoview FV1000, N.A. 1.30, $40 \mathrm{X}$, oil immersion lens). Figure 2 shows time-dependent fluorescence images of live HeLa cells when incubated with QD655-MT. After incubation of HeLa cells with QD655-MT (10 nM) for 1, 2, 4, and $24 \mathrm{hr}$ at $37^{\circ} \mathrm{C}$, each dish of cells was washed with PBS (pH 7.4) and directly observed by confocal microscope. Relatively high fluorescence intensity reached after $1 \mathrm{hr}$ incubation, and the fluorescence appeared exclusively around the plasma membrane. Entry of QD655-MT into HeLa cells occur relatively slowly compared to FITC-MT itself, which was completely taken up within 15 min. ${ }^{15(a)}$ However, when the incubation time was $2 \mathrm{hr}$, punctate figures began to appear inside the cell, suggesting increased internalization of QD655-MT. Up to $4 \mathrm{hr}$ incubation time, more and more QD655-MTs were internalized and accumulated in the intracellular region, with fewer and fewer QD655-MTs on the cell surface. After $24 \mathrm{hr}$ incubation, most QD655-MTs 
(a)

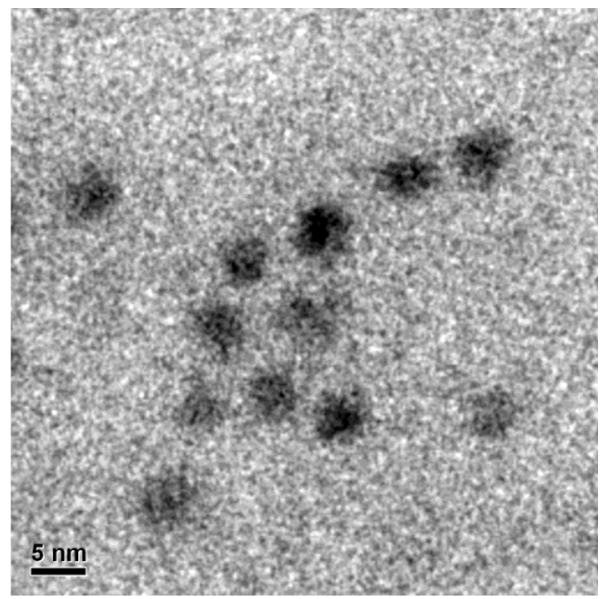

(b)

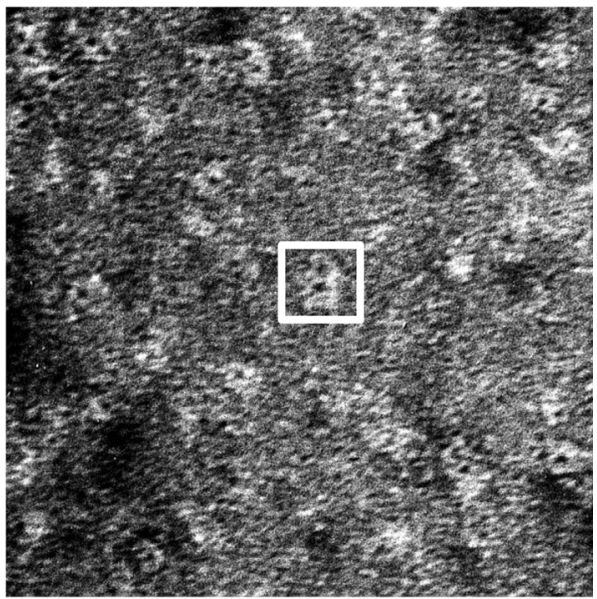

(c)

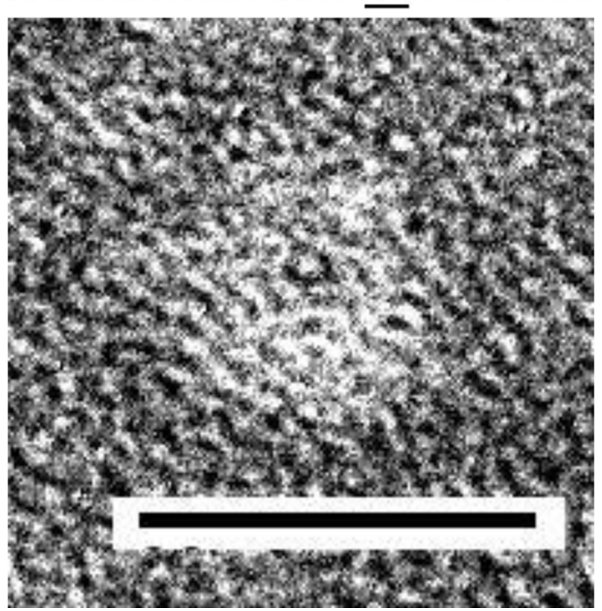

Figure 1. TEM images of QD565-MT on a carbon-coated copper grid. (a) Only the QD part appears as dark granules, (b) Negative staining by $0.5 \%$ uranyl acetate enables to observe both the QD and the streptavidins, (c) Further magnification of the inset in (b) reveals the approximate size of QD565-MT. [scale bar: (a) $5 \mathrm{~nm}$, (b) and (c) $20 \mathrm{~nm}]$

were localized in the perinuclear region (Fig. 2(d)). At 10 $\mathrm{nM}$ concentration of QD655-MT, the required incubation time to obtain reasonable fluorescence intensity inside the cell by confocal microscope is about $4 \mathrm{hr}$. Hence, $4 \mathrm{hr}$ incubation condition was used throughout the study. When QD655 alone was incubated in HeLa cells in the same
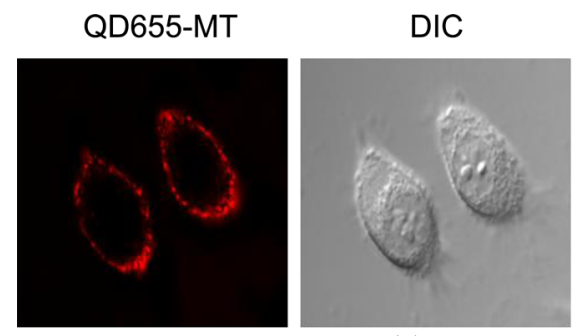

(a) $1 \mathrm{hr}$
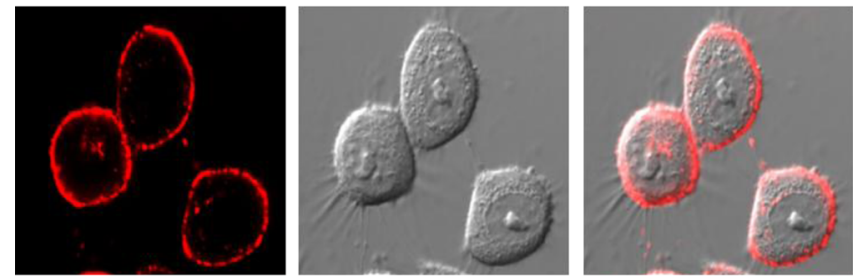

(b) $2 \mathrm{hr}$
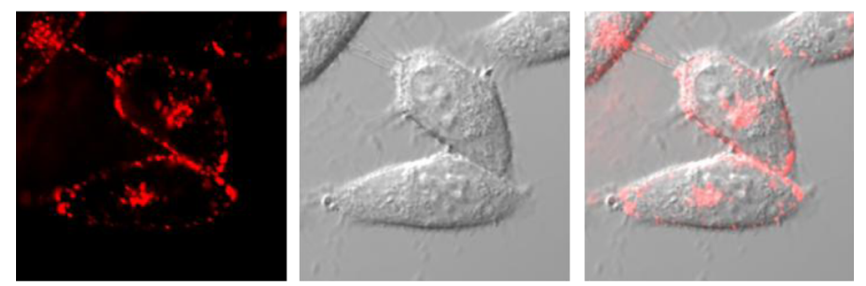

(c) $4 \mathrm{hr}$
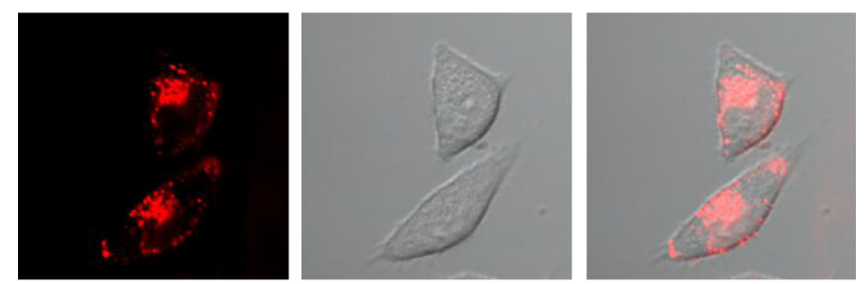

(d) $24 \mathrm{hr}$

Figure 2. Time dependent internalization of QD655-MT (10 nM) in live HeLa cells.

manner, no fluorescence was observed inside the cells, confirming that internalization of QD is only possible with suitable surface modifications (Fig. 1. in supporting information).

To investigate the intracellular localization of QD655MT, subcellular markers were coincubated. QD655-MT was first incubated for $24 \mathrm{hr}$, and then Hoechst33342 (Molecular Probes Inc., $10 \mu \mathrm{M}$, incubated for the last $1 \mathrm{hr}$ ) as nucleus marker and ERtracker green (Molecular Probes Inc., $1 \mu \mathrm{M}$, for the last $30 \mathrm{~min}$ ) as endoplasmic reticulum (ER) marker, were added to the culture media toward the end of the incubation. After washing with PBS (pH 7.4), three different fluorescence signals were recorded by confocal microscope. As shown in Figure 3, QD655-MT has accumulated in the perinuclear region, but not inside the nucleus. As ER is present near the nucleus, ER tracker green also appears in the perinuclear region. The intensity profile along the arrow in the merged image clearly shows no discernible colocalization between QD655-MT and ERtracker green. The data suggest that the major fraction of internalized QD does not traffic either to the ER or to nucleus. 

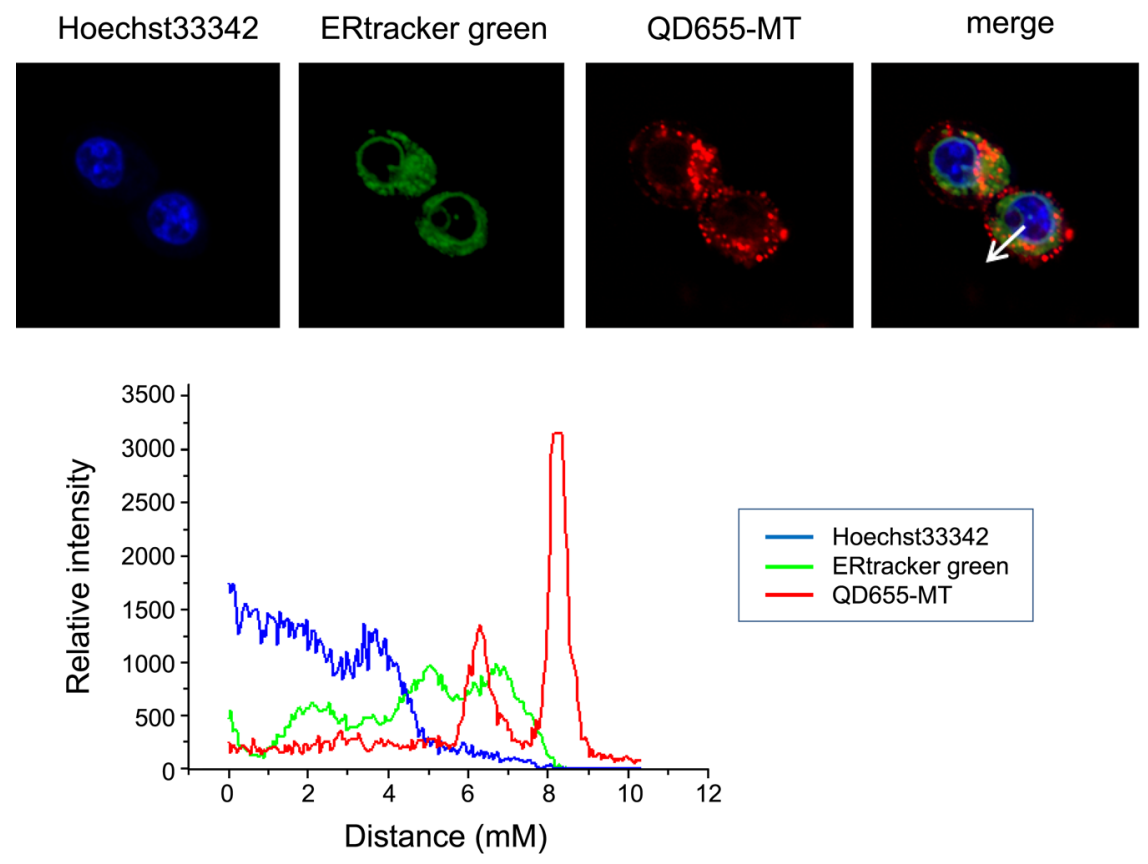

Figure 3. The intracellular localization of QD655-MT (red, $10 \mathrm{nM}, 24 \mathrm{hr}$ incubation) with subcellular markers: Hoechst33342 (blue color, $10 \mu \mathrm{M}, 1 \mathrm{hr}$ incubation) and ERtracker green (green color, $1 \mu \mathrm{M}, 30$ min incubation). The intensity profile along the arrow in the merged image is shown in the graph.
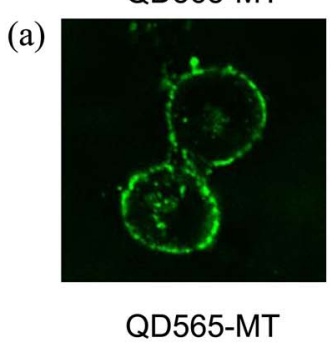

(b)

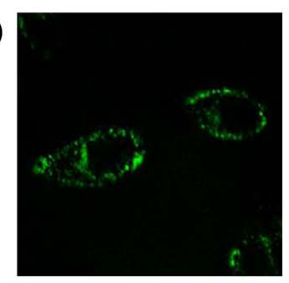

(c)

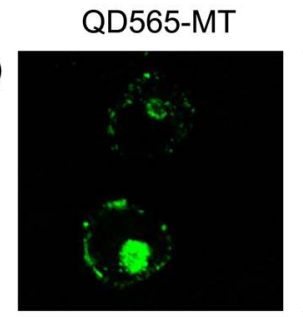

Mitotracker

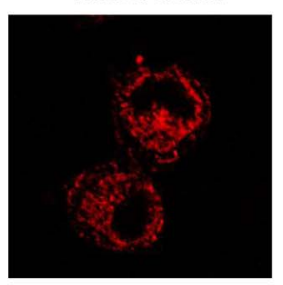

Lysotracker

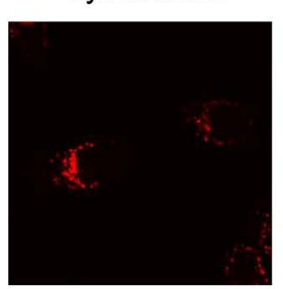

Lysotracker

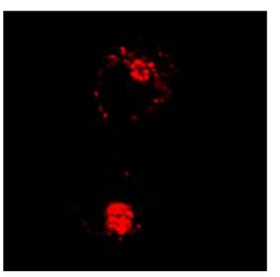

merge

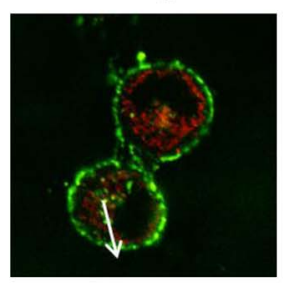

merge

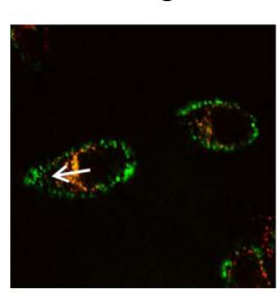

merge

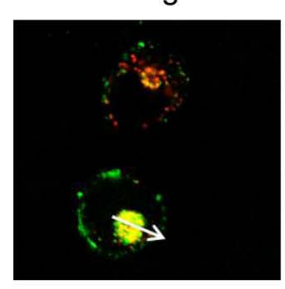

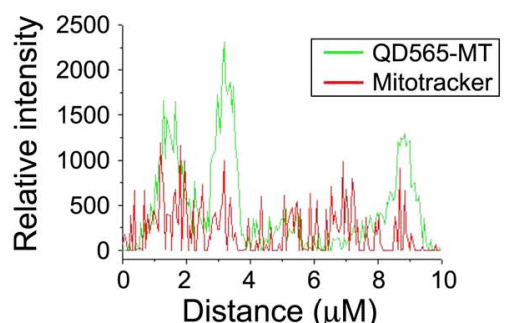
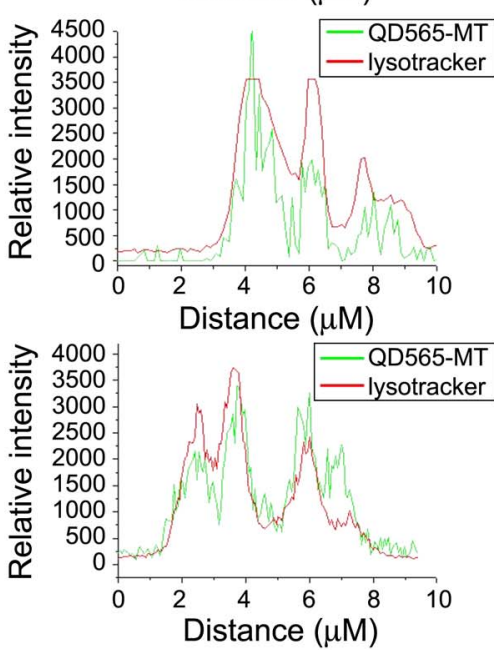

Figure 4. Confocal microscopy images of live HeLa cells. QD565-MT (green) was coincubated with subcellular markers (red). The intensity profiles of the fluorescence signals along the arrows in the merged images are shown on the right. (a) QD565-MT (10 nM, $4 \mathrm{hr}$ incubation) and Mitotracker (100 nM, $30 \mathrm{~min})$; (b) QD565-MT (10 nM, $4 \mathrm{hr}$ incubation) and Lysotracker (200 nM, $30 \mathrm{~min}$ ); (c) QD565MT (10 nM, $24 \mathrm{hr}$ incubation) and Lysotracker (200 nM, $30 \mathrm{~min})$.

The intracellular localization of the QD-MT complex was examined further with Mitotracker and Lysotracker. Since these markers emit the red color fluorescence, QD655-MT was replaced with QD565-MT, in which the excitation and emission ranges do not overlap with those of markers. When HeLa cells were incubated with QD565-MT (10 nM) for 4 


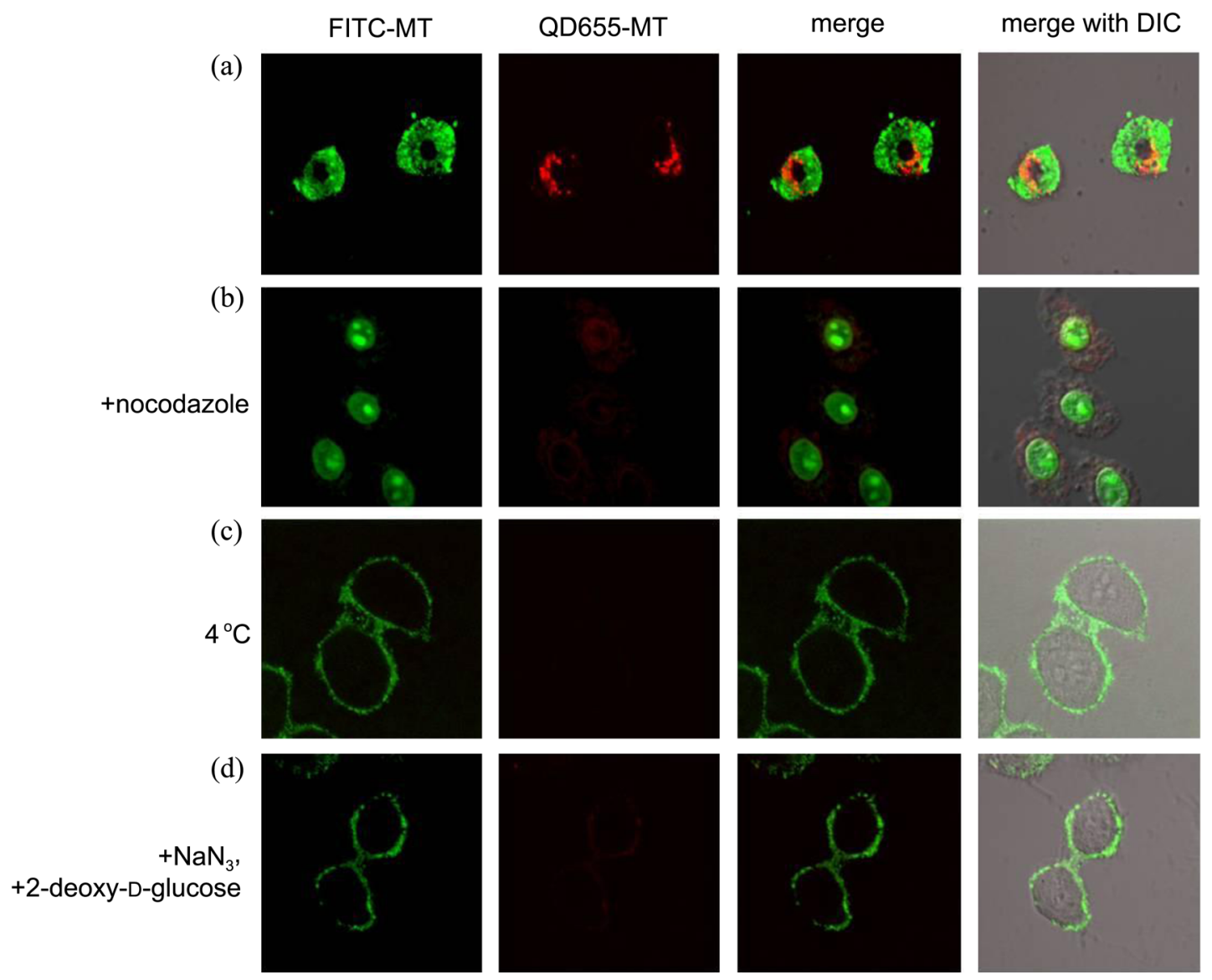

Figure 5. Uptake and intracellular localization of FITC-MT (green, $10 \mu \mathrm{M}, 30$ min incubation) and QD655-MT [red, $10 \mathrm{nM}, 4 \mathrm{hr}$ except (a)] in live HeLa cells (a) coincubation of FITC-MT and QD655-MT (10 nM, $24 \mathrm{hr}$ incubation) under the normal conditions; (b) microtubule disruption by pretreatment with nocodazole $\left(15 \mu \mathrm{M}, 30\right.$ min incubation); (c) incubation at $4{ }^{\circ} \mathrm{C}$, and (d) ATP depletion by pretreatment with $\mathrm{NaN}_{3}$ and 2-deoxy-D-glucose.

$\mathrm{hr}$ and then with Mitotracker $(100 \mathrm{nM})$ for another $30 \mathrm{~min}$, confocal microscope did not exhibit any colocalization (Fig. 4(a)). In contrast, when Lysotracker (200 nM) was similarly coincubated for $30 \mathrm{~min}$, a significant colocalization was observed (Fig. 4(b)). When QD565-MT was increased for $24 \mathrm{hr}$ and then Lysotracker $(200 \mathrm{nM})$ was coincubated for the final $30 \mathrm{~min}$, the merged image and the intensity profile clearly indicate an efficient colocalization (Fig. 4(c)), which in turn suggests that the internalized QD565-MT are trapped in lysosomes.

Comparison of Internalization between FITC-MT and QD-MT. The intracellular localization of QD655-MT was compared with FITC-MT, which contains FITC instead of QD as the probe. The HeLa cells were incubated with QD655-MT (10 nM) for $24 \mathrm{hr}$, and then with FITC-MT (10 $\mu \mathrm{M}$ ) for the last $30 \mathrm{~min}$. After washing with PBS ( $\mathrm{pH} 7.4$ ), the live HeLa cells were examined by confocal microscope. As previously reported, FITC-MT was well dispersed in the cytoplasm, ${ }^{15}$ whereas QD655-MT was largely localized in the perinuclear region. This observation indicates that the intracellular localization patterns are changed depending on the nature of the probe, i.e., small FITC vs. very large QD (Fig. 5(a)).

Nocodazole is a cytoskeleton-disrupting drug commonly used to depolymerize microtubules. In order to see its effect on the uptake and intracellular localization, it was preincubated with HeLa cells for $30 \mathrm{~min}$ prior to the treatment with QD655-MT (10 nM, $4 \mathrm{hr}$ incubation) and FITC-MT (10 $\mu \mathrm{M}, 30 \mathrm{~min}$ incubation). Interestingly, FITC-MT was found to be taken up nicely and localize in the nucleus, while the internalization of QD655-MT was totally blocked (Fig. 5 (b) and Figure 2 in supporting information). This result suggests that microtubules are important for the QD655-MT internalization and the localization in the perinuclear region is most likely caused by microtubule-dependent transport.

Further investigations for the internalization of QD655MT were carried out by employing other inhibition conditions. Endocytosis is an energy-dependent process that may be hindered when incubated at low temperature $\left(4{ }^{\circ} \mathrm{C}\right.$ instead of $37^{\circ} \mathrm{C}$ ) or in the ATP depleted environments (e.g. with $\mathrm{NaN}_{3}$ and 2-deoxy-D-glucose). ${ }^{17,18}$ Thus, incubations of QD655-MT and FITC-MT in HeLa cells were performed at $4{ }^{\circ} \mathrm{C}$ and in the cells pretreated with $\mathrm{NaN}_{3}$ and 2-deoxy-Dglucose. After washing with PBS (pH 7.4), live HeLa cells were observed by confocal microscope maintained with the same instrumental settings (e.g. bandpass, offset, gain, laser power and pinhole size) as before. In contrast to the normal incubation conditions, both FITC-MT and QD655-MT 

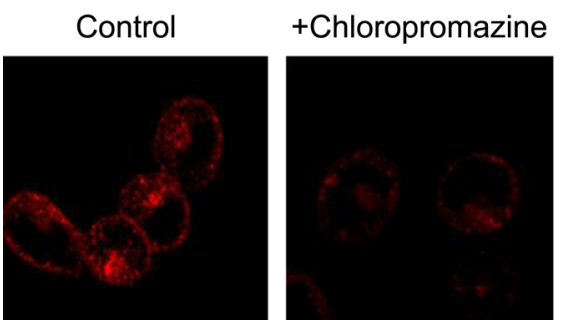

(a)

Transferrin-Texas red conjugate
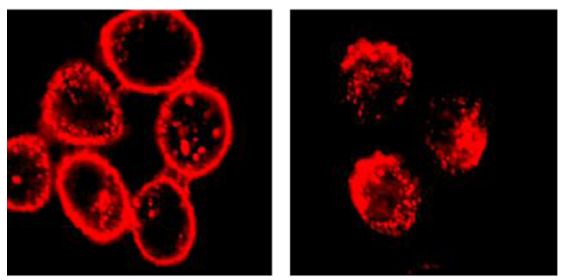

(b)

QD655-MT

Figure 6. Clathrin-mediated endocytosis inhibition in live HeLa cells. Cells were preincubated with either (a) chloropromazine (30 $\mu \mathrm{M}, 30$ min incubation) or (b) sucrose $(0.45 \mathrm{M}, 30$ min incubation) followed by the treatment of transferrin-Texas red conjugate $(25 \mu \mathrm{g}$ $\mathrm{mL}^{-1}, 1 \mathrm{hr}$ incubation) and QD655-MT (10 nM, $4 \mathrm{hr}$ incubation), respectively.

were not internalized under the either conditions, i.e., low temperature or ATP depletion inhibition conditions (Fig. $5(\mathrm{c})$ and (d)). It is quite evident that the cellular uptakes of FITC-MT and QD655-MT are energy-dependent, and that some kind of endocytosis is more likely involved than the passive diffusion.

Internalization Process of QD-MT. To examine the possible role of clathrin in the internalization of QD655MT, incubations were carried out under conditions that are known to disrupt the formation of clathrin-coated pits on the cell membrane, namely pretreating the cells with either sucrose (hypertonic treatment) or the inhibitor, cloropromazine. ${ }^{17(a), 18}$ Transferrin is a well known blood plasma protein that enters cells via clathrin-coated vesicles after binding to the transferrin receptor and traffics through early and recycling endosomes, ${ }^{12}$ and transferrin Texas red conjugate (Molecular Probes Inc.) is used as a reference compound. Thus, HeLa cells were preincubated with either chloropromazine $(30 \mu \mathrm{M})$ or sucrose $(0.45 \mathrm{M})$ for $30 \mathrm{~min}$ at $37^{\circ} \mathrm{C}$ prior to the exposure to transferrin Texas red conjugate (25

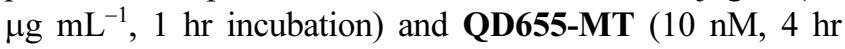
incubation). After washing with PBS (pH 7.4), live HeLa cells were observed by confocal microscope. Control experiments without the inhibitor were also performed. As expected, the fluorescent color (red) from the transferrin conjugate is very dim under both inhibition conditions, indicating the concentrations of chloropromazine and sucrose were high enough for good inhibition (Fig. 6(a)). However, in the case of QD655-MT, the inhibitors had no discernible effect on the cellular uptake (Fig. 6(b)). Thus, it seems that there is little or no involvement of the clathrin-mediated endocytosis for the uptake of QD655-MT.

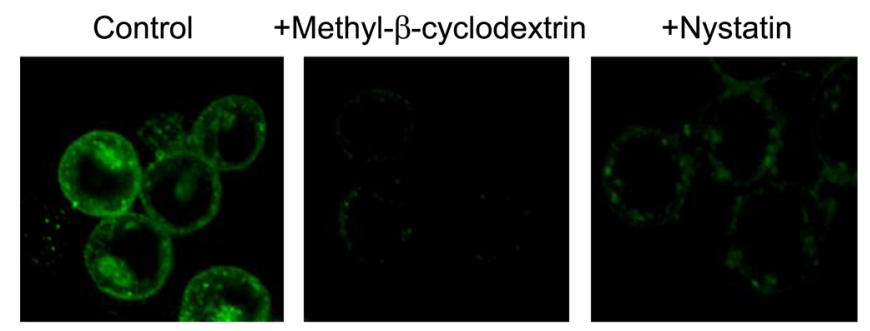

(a)

Cholera toxin B-Alexa488 conjugate
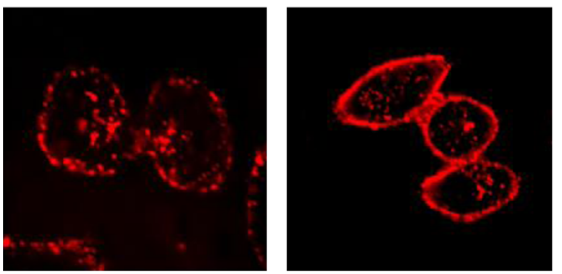

(b)

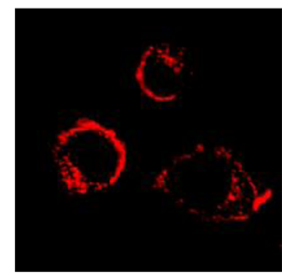

QD655-MT
Figure 7. Caveolae-mediated endocytosis inhibition in live HeLa cells. Cells were preincubated with either (a) methyl- $\beta$-cyclodextrin $(3.5 \mu \mathrm{M}, 30 \mathrm{~min})$ or (b) nystatin $\left(10 \mu \mathrm{g} \mathrm{mL}^{-1}, 30 \mathrm{~min}\right)$ followed by the treatment of cholera toxin B-Alexa488 conjugate $\left(15 \mu \mathrm{g} \mathrm{mL}{ }^{-1}\right.$, $1 \mathrm{hr}$, green) and QD655-MT (10 nM, $4 \mathrm{hr}$, red), respectively.

The possibility of QD655-MT uptake through caveolaemediated endocytosis was also examined. As caveolae is formed in cholesterol and sphingolipid-rich domains within the plasma membrane, the caveolae-mediated endocytosis can be inhibited by incubating the cells with cholesteroldepletion reagents such as methyl- $\beta$-cyclodextrin and nystatin. ${ }^{19}$ Cholera toxin subunit $\mathrm{B}$ is relatively nontoxic and commonly used in molecular cell biology experiments. It binds to the GM1 gangliosides receptor which resides mostly in the caveolae. ${ }^{17(a)}$ As cholera toxin B is delivered into cells via caveolae-mediated endocytosis, cholera toxin BAlexa488 conjugate (Molecular Probes Inc.) is used as a reference compound. Thus, HeLa cells were preincubated with either methyl- $\beta$-cyclodextrin $(3.5 \mu \mathrm{M})$ or nystatin $(10$ $\mu \mathrm{g} \mathrm{mL} L^{-1}$ ) for $30 \mathrm{~min}$ at $37^{\circ} \mathrm{C}$ prior to the exposure to cholera toxin B Alexa488 conjugate (15 $\mu \mathrm{g} \mathrm{mL} \mathrm{m}^{-1}, 1 \mathrm{hr}$ incubation) and QD655-MT (10 nM, $4 \mathrm{hr}$ incubation). After washing with PBS (pH 7.4), live HeLa cells were observed by confocal microscope. Control experiments without inhibitors were performed as well. As expected, the fluorescent color (green) from the cholera toxin B conjugate is very dim in the presence of inhibitors, indicating the concentrations of methyl- $\beta$-cyclodextrin and nystatin are high enough for inhibition (Fig. 7(a)). Under the identical inhibition conditions, translocation of QD655-MT into the cell is not noticeably diminished, indicating that the caveolae-mediated endocytosis is not a major pathway for QD655-MT (Fig. $7(b))$.

Finally, the possibility of QD655-MT uptake through macropinocytosis pathway was investigated using inhibitors. 5 -( $N$-ethyl- $N$-isopropyl)amiloride (EIPA) is a $\mathrm{Na}^{+} / \mathrm{H}^{+}$exchange protein inhibitor, and known to inhibit macro- 


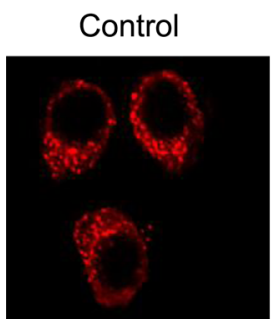

+Wortmannin

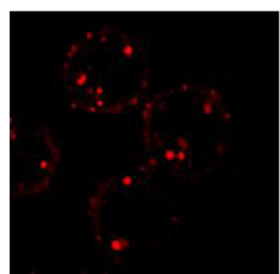

(a)

Dextran rhodamine B conjugate
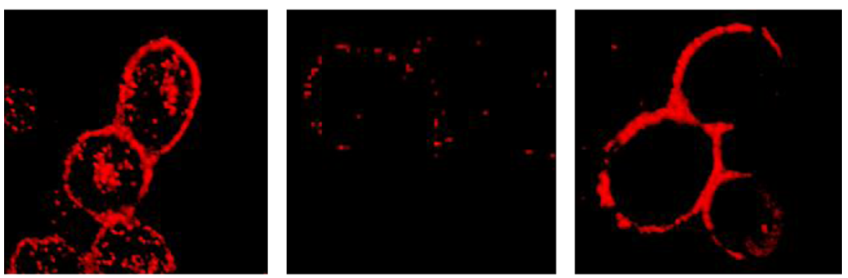

(b)

QD655-MT

Figure 8. Macropinocytosis inhibition in live HeLa cells. Cells were preincubated with either (a) wortmannin ( $100 \mathrm{nM}, 30$ min incubation) or (b) EIPA (100 $\mu \mathrm{M}, 30 \mathrm{~min})$, followed by the treatment of dextran Rhodamine B conjugate (1 $\left.\mathrm{mg} \mathrm{mL}^{-1}, 1 \mathrm{hr}\right)$ and QD655-MT (10 nM, $4 \mathrm{hr}$ ), respectively.

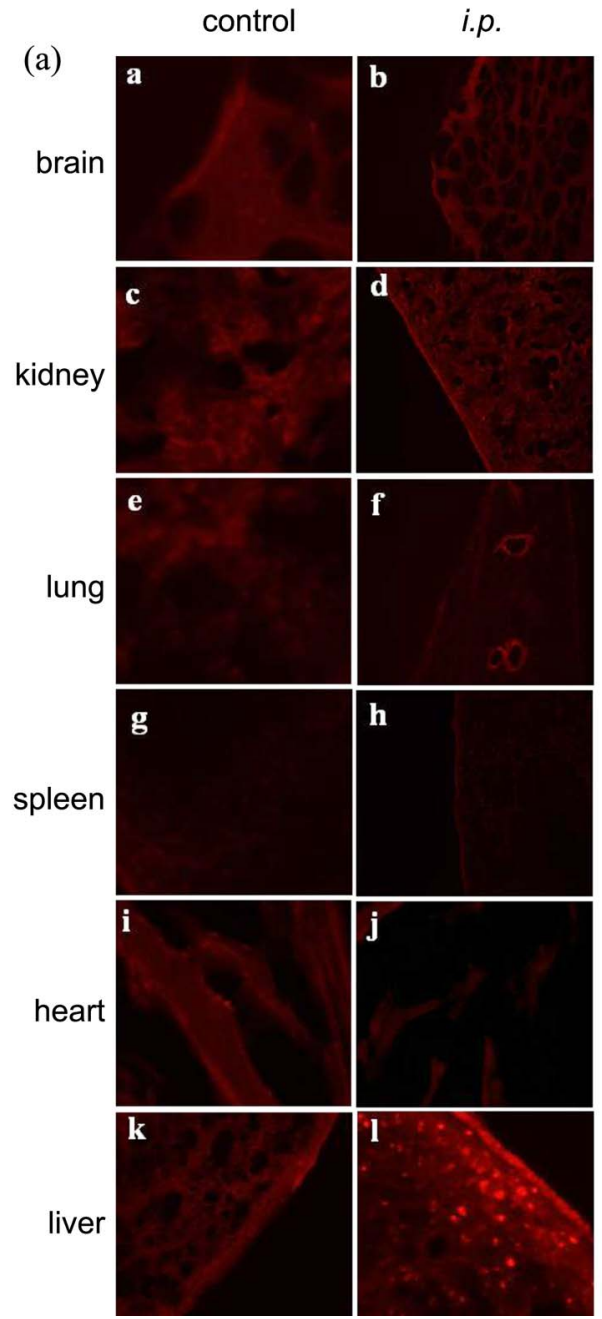

(b)

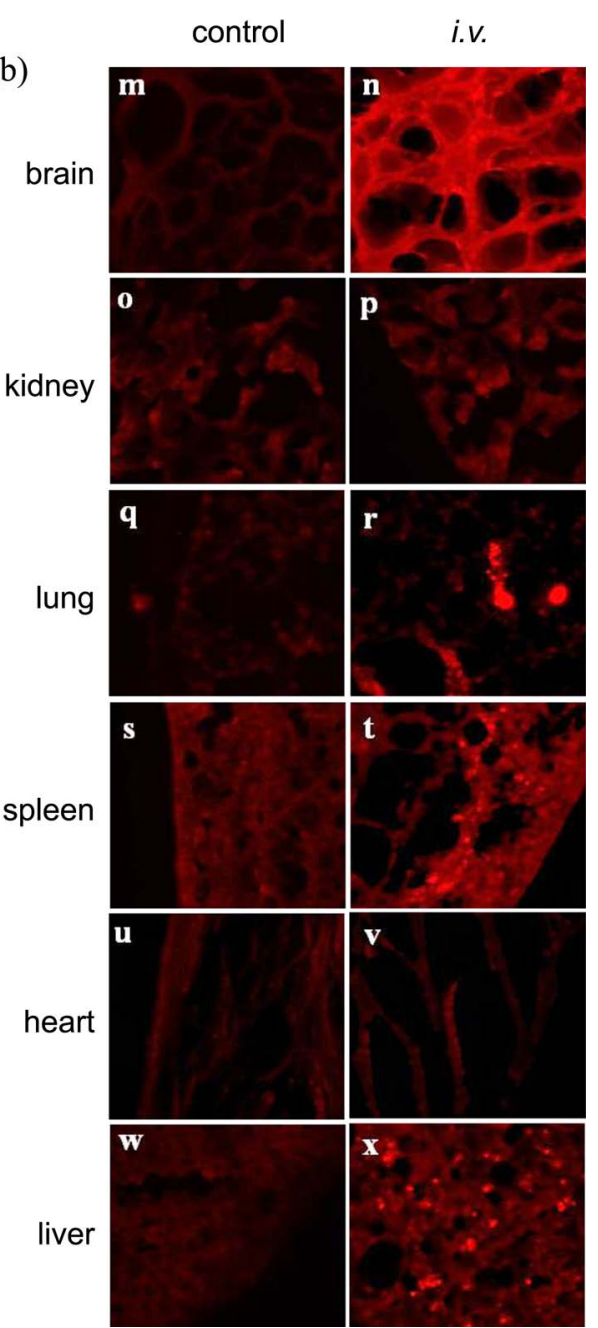
(Fig. 8(b)), indicating that the internalization of QD655-MT is efficiently blocked by both inhibitors. On the basis of these results it may be concluded that macropinocytosis is

Figure 9. Distribution of QD655-MT in mice tissues. (a) i.p. and (b) i.v. Exposure times (ms): brain, 8000; kidney, 3000; lung, 7000; spleen, 3000 , heart, 2000; liver, 1000. Tissues isolated from mice $24 \mathrm{hr}$ after i.p. and i.v. injection. $\lambda_{\max }=543 \mathrm{~nm}$ (red fluorescence from QD). 
the major pathway for the internalization of QD655-MT, which is consistent with previous observation with other CPP mediated uptake of QDs. ${ }^{8(b),(c)}$

Mouse Tissue Distribution of QD-MT. A solution of QD655-MT (0.2 nmol) in PBS (pH 7.4, $500 \mu \mathrm{L})$ was prepared, and injected to an eight-week-old mouse (C57BL/ 6) by i.p. route. After $24 \mathrm{hr}$, the treated mouse was perfused with 4\% paraformaldehyde in phosphate buffer solution (PBS; pH 7.4). The organs (brain, heart, spleen, kidney, lung, and liver) were harvested, incubated overnight in sucrose solution in PBS (0.5 M). Placed in cryoprotectant, they were cut into $15 \mu \mathrm{m}$ sections with cryostat, and transferred to coated glass slides. After drying at $37{ }^{\circ} \mathrm{C}$, the sections were washed with PBS, treated with $0.3 \%$ Triton X-100 for 15 min at rt, and analyzed with an Axioplan2 fluorescence imaging microscope. No significant fluorescence was seen in organs other than liver (Fig. 9(a)). Granular spots are noted in the liver, as possible aggregates of QD655-MT. It appears that most of the QD-MT was trapped in liver.

Intravenous (i.v.) route was also examined for possible variation. Thus, a solution of QD655-MT ( $0.2 \mathrm{nmol})$ in PBS ( $\mathrm{pH} 7.4,500 \mu \mathrm{L}$ ) was prepared, and slowly injected to an eleven-week-old mouse (C57BL/6) via tail vein. No unusual behavioral change of treated mice was noticed in both experiments. After $24 \mathrm{hr}$, the mouse was treated as described for the i.p. In the case of the i.v. administration, fluorescence was observed in brain, lung, and spleen in addition to liver (Fig. 9(b)). The image of liver appears similar to that of i.p. experiment (Fig. 9(b)-x). However, the brain image shows a highly diffused pattern without many granular spots (Fig. 9(b)-n).

\section{Conclusions}

Although QD is considered a more promising fluorescent probe than conventional organic dyes, it requires a surface modification to be efficiently taken up by cells. A biotinattached G8 sorbitol-based molecular transporter (5, MT), when complexed with quantum dots containing streptavidins, was found to facilitate the internalization into HeLa cells. QD655-MT complex appears to physically bind first in the plasma membrane in $1 \mathrm{hr}$, whereas the MT itself (FITC-MT) is almost completely internalized into the cytoplasm within $15 \mathrm{~min}$. Perhaps due to the much bigger size of QD-MT (ca. 18-20 nm), the cellular uptake of QD655-MT is much slower than that of FITC-MT. As the incubation time increases to more than $2 \mathrm{hr}$, QD655-MT begins to be internalized by macropinosomes with the help of microtubules, randomly appearing in the cytoplasm and vesicles such as endosomes or lysosomes. In $24 \mathrm{hr}$, most QD655-MT are localized in the perinuclear region, but not inside the nucleus. The observation that QD655-MT efficiently crosses the BBB to gain an entry into brain tissue, when given to a mouse by tail vein, is very interesting as QD is generally believed too large to cross the $\mathrm{BBB} .^{21}$

Acknowledgments. Financial Support from BK21 and
National Frontier Research Program of Korean MOEST (administered via KRICT/CBM) is gratefully acknowledged.

\section{References}

1. (a) Parak, W. J.; Pellegrino, T.; Plank, C. Nanotechnology 2005, 16, R9. (b) Jaiswal, J. K.; Mattoussi, H.; Mauro, J. M.; Simon, S. M. Nat. Biotechnol. 2003, 21, 47. (c) Medintz, I. L.; Uyeda, H. T.; Goldman, E. R.; Mattoussi, H. Nat. Mater. 2005, 4, 435.

2. (a) Giepmans, B. N. G.; Deerinck, T. J.; Smarr, B. L.; Jones, Y. Z.; Ellisman, M. H. Nat. Methods, 2005, 2, 743. (b) Nisman, R.; Dellaire, G.; Ren, Y.; Li, R.; Bazett-Jones, D. P. J. Histochem. Cytochem. 2004, 52, 13.

3. (a) Dahan, M.; Levi, S.; Luccardini, C.; Rostaing, P.; Riveau, B.; Triller, A. Science 2003, 302, 442. (b) Courty, S.; Luccardini, C.; Bellaiche, Y.; Cappello, G.; Dahan, M. Nano Lett. 2006, 6, 1491. (c) Smith, A. M.; Daun, H.; Mohs, A. M.; Nie, S. Adv. Drug Delivery Rev. 2008, 60, 1226.

4. (a) Derfus, A. M.; Chan, W. C.; Bhatia, S. N. Adv. Mater. 2004, 16, 961. (b) Tsong, T. Y. Biophys. J. 1991, 60, 297.

5. (a) Medintz, I. L.; Pons, T.; Delehanty, J. B.; Susumu, K.; Brunel, F. M.; Dawson, P. E.; Mattoussi, H. Bioconjugate Chem. 2008, 19, 1785. (b) Yum, K.; Na, S.; Xiang, Y.; Wang, N.; Yu, M. F. Nano Lett. 2009, 9, 2193.

6. Voura, E. B.; Jaiswal, J. K.; Mattoussi, H.; Simon, S. M. Nat. Med. 2004, 10, 993

7. (a) Walther, C.; Meyer, K.; Rennert, R.; Neundor, I. Bioconjugate Chem. 2008, 19, 2346. (b) Chen, F.; Gerion, D. Nano Lett. 2004, 4, 1827. (c) Rozenzhak, S. M.; Kadakia, M. P.; Caserta, T. M.; Westbrook, T. R.; Stone, M. O.; Naik, R. R. Chem. Commun. 2005, 2217. (d) Zhelev, Z.; Ohba, H.; Bakalova, R.; Jose, R.; Fukuoka, S.; Nagase, T.; Ishikawa, M.; Baba, Y. Chem. Commun. 2005, 1980.

8. (a) Liu, B. R.; Li, J. F.; Lu, S. W.; Lee, H. J.; Huang, Y. W.; Shannon, K. B.; Aronstam, R. S. J. Nanosci. Nanotechnol. 2010 10, 6534. (b) Ruan, G.; Agrawal, A.; Marcus, A. I.; Nie, S. J. Am. Chem. Soc. 2007, 129, 14759. (c) Chen, B.; Liu, Q.; Zhang, Y.; Xu, L.; Fang, X. Langmuir 2008, 24, 11866.

9. Conner, S. D.; Schmid, S. L. Nature 2003, 422, 37.

10. Schutze, S.; Tchikov, V.; Schneider-Brachert, W. Nat. Rev. Mol. Cell Biol. 2008, 9, 655 .

11. (a) Jones, A. T. J. Cell. Mol. Med. 2007, 11, 670. (b) Mercer, J.; Helenius, A. Nat. Cell Biol. 2009, 11, 510.

12. (a) Schmid, S. L. Annu. Rev. Biochem. 1997, 66, 511. (b) Brodsky, F. M.; Chen, C.-Y.; Kneuhl, C.; Towler, M. C.; Wakeham, D. E. Annu. Rev. Cell Dev. Biol. 2001, 17, 517.

13. Puri, V.; Watanabe, R.; Singh, R. D.; Dominguez, M.; Brown, J. C.; Wheatley, C. L.; Marks, D. L.; Pagano, R. E. J. Cell Biol. 2001, 154, 535 .

14. Nichols, B. J.; Lippincott-Schwartz Trends Cell Biol. 2001, 11, 406.

15. (a) Maiti, K. K.; Lee, W. S.; Takeuchi, T.; Watkins, C.; Fretz, M.; Kim, D. C.; Futaki, S.; Jones, A.; Kim, K.-T.; Chung, S. K. Angew. Chem. Int. Ed. 2007, 46, 5880. (b) Chung, S. K.; Maiti, K K.; Lee, W. S. Int. J. Pharm. 2008, 354, 16.

16. (a) Im, J.; Kim, W.; Kim, K. T.; Chung, S. K. Chem. Commun 2009, 4649. (b) Im, J.; Biswas, G.; Kim, W.; Kim, K.-T.; Chung, S. K. Bull. Korean Chem. Soc. 2011, in press. (c) Jin., J.; Lee, W. S.; Joo, K. M.; Maiti, K. K.; Biswas, G.; Kim, W.; Kim, K.-T.; Lee, S. J.; Kim, K.-H.; Nam, D.-H.; Chung, S. K. Med. Chem. Commun. 2011. DOI $10.1039 /$ comd00235f

17. (a) Kam, N. W. S.; Liu, Z.; Dai, H. Angew, Chem. Int. Ed. 2005 , 44, 1. (b) Richard, J. P.; Melikov, K.; Brooks, H.; Prevot, P.; Lebleu, B.; Chernomordik, L. V. J. Biol. Chem. 2005, 280, 15300.

18. (a) Gao, X.; Wang, T.; Wu, B.; Chen, J.; Chen, J.; Yue, Y.; Dai, N.; Chen, X.; Jiang, X. Biochem. Biophys. Res. Commun. 2008, 377, 35. (b) Mo, Y.; Lim, L. Y. J. Pharm. Sci. 2004, 93, 20. 
19. (a) Wadia, J. S.; Stan, R. V.; Dowdy, S. F. Nat. Med. 2004, 10, 310. (b) Zhang, L. W.; Monteiro-Riviere, N. A. Toxicol. Sci. 2009, 110, 138.

20. (a) Battah, S.; Balaratnam, S; Casas, A; O'Neill, S; Edwards, C; Batlle, A; Dobbin, P.; MacRobert, A. J. Mol. Cancer Ther. 2007,
6, 876. (b) Bellette, B. M.; Woods, G. M.; Wozniak, T.; Doherty, K. V.; Muller, H. K. Immunology 2003, 110, 466.

21. Santra, S.; Yang, H.; Stanley, J. T.; Holloway, P. H.; Moudgil, G. W.; Mericle, R. A. Chem. Commun. 2005, 3144. 